Article

\title{
Antifouling Studies of Unsymmetrical Oligo(ethylene glycol) Spiroalkanedithiol Self-Assembled Monolayers
}

\author{
Lydia R. St. Hill ${ }^{1}$, Hung-Vu Tran ${ }^{1}$, Pawilai Chinwangso ${ }^{1}$, Han Ju Lee ${ }^{1}$, Maria D. Marquez ${ }^{1}$, John W. Craft, Jr. ${ }^{2} \mathbb{D}$ \\ and T. Randall Lee ${ }^{1, *(D)}$ \\ 1 Department of Chemistry and the Texas Center for Superconductivity, University of Houston, \\ 4800 Calhoun Road, Houston, TX 77204-5003, USA; Irsthill@central.uh.edu (L.R.S.H.); \\ hvtran2@central.uh.edu (H.-V.T.); pawilaichinwangso@yahoo.com (P.C.); hanju.lee73@gmail.com (H.J.L.); \\ mdmarquez2@uh.edu (M.D.M.) \\ 2 Department of Biology and Biochemistry, University of Houston, 4800 Calhoun Road, \\ Houston, TX 77204-5003, USA; jwcraft@central.uh.edu \\ * Correspondence: trlee@uh.edu
}

check for updates

Citation: St. Hill, L.R.; Tran, H.-V.; Chinwangso, P.; Lee, H.J.; Marquez, M.D.; Craft, J.W., Jr.; Lee, T.R.

Antifouling Studies of

Unsymmetrical Oligo(ethylene glycol) Spiroalkanedithiol Self-Assembled Monolayers. Micro 2021, 1, 151-163. https://doi.org/10.3390/ micro1010012

Academic Editor: Ewa Kowalska

Received: 24 June 2021

Accepted: 17 August 2021

Published: 1 September 2021

Publisher's Note: MDPI stays neutral with regard to jurisdictional claims in published maps and institutional affiliations.

Copyright: (c) 2021 by the authors. Licensee MDPI, Basel, Switzerland. This article is an open access article distributed under the terms and conditions of the Creative Commons Attribution (CC BY) license (https:// creativecommons.org/licenses/by/ $4.0 /)$.

\begin{abstract}
The antifouling properties of self-assembled monolayers (SAMs) on gold generated from custom-designed bidentate unsymmetrical spiroalkanedithiols containing both oligo(ethylene glycol) and hydrocarbon tailgroups (EG3C7-C7 and EG3C7-C18) were evaluated and compared to SAMs derived from analogous monodentate octadecanethiol $(\mathrm{C} 18 \mathrm{SH})$ and the tri(ethylene glycol)-terminated alkanethiol EG3C7SH. Complementary techniques, including in situ surface plasmon resonance spectroscopy (SPR), ex situ electrochemical quartz crystal microbalance (QCM) measurements, and ex situ ellipsometric thickness measurements, were employed to assess the protein resistance of the SAMs using proteins having a wide range of sizes, structures, and properties: protamine, lysozyme, bovine serum albumin (BSA), and fibrinogen. The studies found that SAMs generated from the bidentate adsorbates EG3C7-C7 and EG3C7-C18, which contain a 1:1 mixture of OEG and hydrocarbon tailgroups, exhibited a diminished capacity to resist protein adsorption compared to the EG3C7SH SAMs, which possess only OEG tailgroups. The data highlight the critical role of hydration of the OEG matrix for generating antifouling OEG-based surface coatings.
\end{abstract}

Keywords: antifouling; self-assembled monolayers; oligo(ethylene glycol); spiroalkanedithiols; surface plasmon resonance; quartz crystal microbalance; ellipsometry

\section{Introduction}

Due to their ability to resist the adsorption of proteins and other macromolecules, coatings based on biocompatible poly(ethylene glycol) (PEG), also known as poly(ethylene oxide) (PEO), have been used in many clinical and biological applications [1-3]. In particular, PEG-coated surfaces have been incorporated into membranes [4,5], biosensors $[3,6]$, and many biomolecular devices $[2,7,8]$ that require interfacial contact with biological environments. PEG-based polymeric coatings, however, are often difficult to characterize with accuracy and reliability due to their morphologically rough and non-uniform interfaces [9]. In contrast, surface coatings based on oligo(ethylene glycol) (OEG) moieties with two to six monomer units are markedly easier to characterize and have proven equally effective in resisting protein adsorption [10-13]. Consequently, self-assembled monolayers (SAMs) containing OEG-terminated alkanethiols on gold have been used as model systems for generating well-defined interfaces that enable studies of the fundamental structure-property relationships needed for designing optimal antifouling coatings [14-19].

Although mechanistically ill-defined, the strong interaction of water with PEG and OEG chains is paramount for the resistance to adsorption of proteins on PEG- and OEGcontaining surfaces $[14,20,21]$. Andrade and co-workers proposed that when proteins approach high-molecular-weight PEG, there is a repulsive entropic effect, termed "steric 
repulsion," which arises from the unfavorable change in free energy associated with dehydration corresponding to a reduction in the degrees of conformational freedom of the polymer chains $[22,23]$. This steric repulsion is important for the antifouling properties of surfaces possessing PEG chains. Notably, however, densely packed OEG films show adhesive resistance to proteins, even though the conformational freedom of the OEG chains is restricted [24]. Moreover, Grunze [25,26] and other researchers [27-29] suggested that the penetration of water molecules in the interior of OEG SAMs is essential for their protein resistance. Thus, the interaction of water with PEG and OEG surfaces is intrinsically involved in the antifouling performance of these organic thin films.

A major concern and limiting factor in the use of monodentate thiol-based SAMs as coating materials is the moderate stability of the films. Specifically, $n$-alkanethiol SAMs on gold substrates undergo facile desorption at temperatures as low as $\sim 70{ }^{\circ} \mathrm{C}$ [30]. To address this shortcoming, bidentate thiol-based adsorbates that enable multiple attachment points between an adsorbate molecule and a gold substrate have been developed [31-37]. The enhanced stability of bidentate thiol-based SAMs on gold arises from the entropydriven "chelate effect" [31]. Another advantage of bidentate adsorbates is the ability to incorporate two different terminal groups into the same molecule, which offers flexibility in film composition, allowing the generation of unique nanoscale interfaces composed of phase-incompatible chemical entities [34,35]; these "conflicted" interfaces are comprised of chemically disparate species held in close proximity [34,35,38-41]. Recently, we reported that "conflicted" SAM-based interfaces generated from bidentate spiroalkanedithiols possessing mixed hydrocarbon and fluorocarbon tailgroups exhibit enhanced protein resistance when compared to SAMs generated from their single-component monodentate counterparts [41]. Moreover, the generation of SAMs from dithiol-based adsorbates permits studies of the behavior and properties of interfaces consisting of homogeneously mixed disparate chemical species [38-41] that would typically phase-separate to form surfaces having patches of single-component domains [42-46].

As noted above, numerous studies have shown that SAMs generated from tri(ethylene glycol)-terminated alkanethiols on gold exhibit excellent protein resistance [12,14,15]. Moreover, protein resistance is observed in OEG SAMs terminated with either methoxy or hydroxy groups [12]. We previously reported the preparation of SAMs from unsymmetrical spiroalkanedithiol bidentate adsorbates containing one methoxy-terminated tri(ethylene glycol) chain and one $n$-alkanethiol chain [39] (see EG3C7-C7 and EG3C7-C18 in Figure 1). We found during preliminary examination of the antifouling behavior of these "conflicted" interfaces using ellipsometry to measure the adsorption of the single protein fibrinogen [39] that the SAM interfaces containing a mixture of OEG and hydrocarbon groups were less fibrinogen resistant than the OEG interfaces alone. To examine in greater detail this phenomenon using a wider variety of proteins (protamine, lysozyme, bovine serum albumin (BSA), and fibrinogen) and a wider range of characterization techniques (quartz crystal microbalance (QCM), surface plasmon resonance (SPR), as well as ellipsometry), the present investigation seeks to explore in a broader sense whether the SAMs generated from EG3C7-C7 and EG3C7-C18 show a diminished ability to resist protein adsorption compared to the SAMs possessing only OEG-terminated chains generated from EG3C7SH. This investigation further highlights the paramount role of strong water-surface interactions for generating antifouling organic thin-film coatings. 


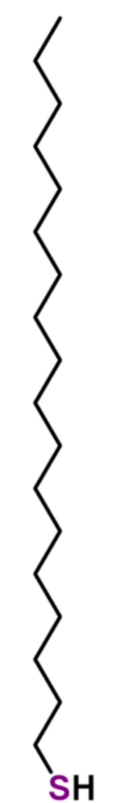

C18SH

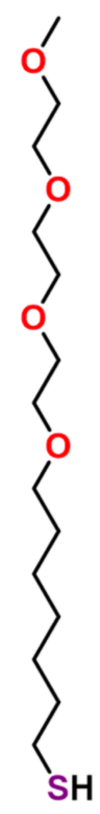

EG3C7SH

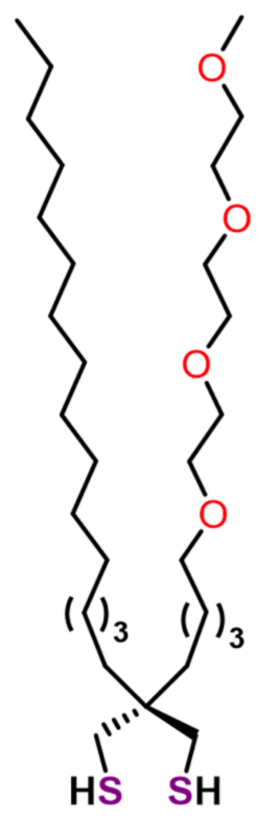

EG3C7-C18

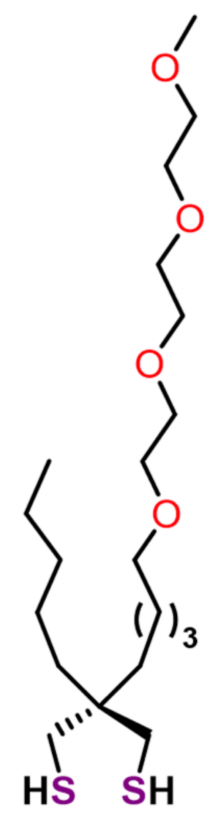

EG3C7-C7

Figure 1. Molecular structures of the monodentate $\mathrm{C} 18 \mathrm{SH}$ and $\mathrm{EG} 3 \mathrm{C} 7 \mathrm{SH}$, as well as $\mathrm{C} 7-\mathrm{C} 18$ and EG3C7-C7 adsorbates analyzed in this study.

\section{Materials and Methods}

\subsection{Materials}

All chemicals were used as received, unless otherwise noted. Absolute ethanol (200 proof) was purchased from Decon Labs, Inc. (King of Prussia, PA, USA) and tetrahydrofuran (THF), sulfuric acid $\left(\mathrm{H}_{2} \mathrm{SO}_{4}\right)$, and hydrogen peroxide $\left(30 \% \mathrm{H}_{2} \mathrm{O}_{2}\right)$ from Avantor Performance Materials (Radnor, PA, USA). Protamine, lysozyme, bovine serum albumin, fibrinogen, and 1octadecanethiol (C18SH) were purchased from Sigma-Aldrich (St. Louis, MO, USA). The other adsorbates, 2,5,8,11-tetraoxaoctadecane-18-thiol (EG3C7SH), 2-(2,5,8,11-tetraoxahexadecane16-yl)-2-hexadecylpropane-1,3-dithiol (EG3C7-C18), and 2-(2,5,8,11-tetraoxahexadecane-16yl)-2-pentylpropane-1,3-dithiol (EG3C7-C7), were synthesized according to procedures found in the literature [39]. Phosphate buffer solution (PBS) 10× from GenDepot (Barker, TX, USA) was diluted to $1 \times$ using water $\left(\mathrm{H}_{2} \mathrm{O}\right)$ having a resistance of $18.2 \mathrm{M} \Omega$ generated from a Milli-Q water system.

Gold shot (99.999 \%) was purchased from Kamis, Inc. (Mahopac Falls, NY, USA), and chromium rods (99.9\%) were purchased from Kurt J. Lesker Company (Jefferson Hills, PA, USA) and used as received. Polished single-crystal Si(100) wafers were purchased from University Wafer, Inc. (Boston, MA, USA) and were rinsed with absolute ethanol before use. SPR sensors composed of $500 \AA$ of Au platted on Ti-coated silica substrates were purchased from Sofchip (Sebring, FL, USA). QCM sensors composed of polished AT-cut quartz crystals oscillating at a $10 \mathrm{MHz}$ frequency coated with Ti and plated with $1000 \AA$ of gold were purchased from the International Crystal Manufacturing Company, Inc. (Oklahoma City, OK, USA).

\subsection{Preparation of Substrates}

Thermal evaporation of gold onto Si(100) wafers at a vacuum pressure of $\leq 6 \times 10^{-5}$ torr was used to prepare gold substrates used in ellipsometric thickness measurements. Initially, a $100 \AA$ A chromium adhesion layer was deposited, followed by a $1000 \AA$ gold layer deposited at a rate of $0.5 \AA / s$. SPR and QCM sensors required submersion in piranha solution, rinsing with copious amounts of Milli-Q water, followed by absolute ethanol, and then drying in a 
stream of ultra-pure nitrogen gas immediately prior to SAM preparation. Caution: Piranha solution reacts violently with organic materials and should be handled carefully!

\subsection{Preparation of SAMs}

Prior to preparation of adsorbate solutions, all vials were cleaned with piranha solution and then rinsed with copious amounts of deionized water followed by absolute ethanol. Each respective gold substrate (evaporated gold, QCM sensors, SPR sensors) was prepared by submersion in a $1 \mathrm{mM}$ solution of the respective thiols in absolute ethanol solution. The SAMs were placed in a dark environment at room temperature for $48 \mathrm{~h}$ to equilibrate. All SAMs were rinsed with THF followed by absolute ethanol and then dried with a stream of ultra-pure nitrogen before use.

\subsection{Protein Preparation/Exposure}

Protein solutions were prepared by dissolving $1 \mathrm{mg}$ of protein in $1 \mathrm{~mL}$ of PBS and then sonicated for $15 \mathrm{~min}$. Prior to use, all protein solutions and buffers were filtered through a $0.2 \mu \mathrm{m}$ filter. The SPR sensors were exposed to the protein solutions via automated injection using a Biacore 2000 instrument and an automated protocol to measure in situ interactions with the protein solutions. The remaining substrates (thermally evaporated Au samples and QCM sensors) were submerged into the protein solutions for $1 \mathrm{~h}$ to allow protein adsorption on the SAMs to reach saturation. Upon removal, the substrate samples were rinsed first with PBS buffer followed by Milli-Q water and then dried with a stream of ultra-pure nitrogen gas.

\subsection{SPR Procedures}

A Biacore 2000 instrument was used to obtain SPR sensorgrams. The SPR sensors containing the SAMs were inserted into the Biacore 2000 instrument and exposed to PBS buffer running at a rate of $30 \mu \mathrm{L} / \mathrm{min}$. Through an automated program, $300 \mu \mathrm{L}$ injections of a protein solution at a concentration of $1 \mathrm{mg} / \mathrm{mL}$ were injected into each respective channel. The buffer continued to flow over each channel, and the measurements were recorded for an additional $2 \mathrm{~h}$ following every injection on each channel. The flow of PBS buffer over surfaces after exposure to protein solutions allows any unbound or weakly attached protein to be washed away. Application of Kretschmann theory in this SPR technique allows the generation of sensorgrams [47]. Specifically, a sensorgram is generated due to a change in the resonance angle of light reflected from the Au surface. The change in mass associated with the interaction of the protein with the surface via binding and disassociation gives rise to a change in the angle of reflection of the light from the surface of the sensor. A signal is generated in the sensorgram that reflects an increase in the signal for protein interaction and a decrease for protein removal as a response to the change in the refractive index at the interface of the surface. Each newly generated surface was exposed to each protein solution on the respective channel, and the reported values are an average of 3 trials and include the standard deviation. The reported values of $\Delta R U$ correspond to the difference between the ground response and the final response after protein exposure and the flow of the buffer.

\subsection{QCM Measurements}

A Gamry electrochemical quartz crystal microbalance (eQCM) was used to simultaneously measure the parallel and series frequency measurements $(f)$ of functionalized QCM sensors at the bare gold surface and the SAM before and after exposure to protein. The QCM maintains a continuous driving voltage to the piezoelectric crystal, and the reported values are an average of the resonant frequencies after stabilization. The resonant frequencies are generated once a voltage is applied to a thin AT-cut piezoelectric crystal that is sandwiched between two Au plates. The applied voltage produces an alternating electric field on each side of the crystal, which leads to the generation of a mechanical shear wave modulate and a vibrational motion, thus producing the resonant frequency for the 
crystal. A change in the resonant frequency can be observed with small mass losses or gains. An increase in mass will cause a decrease in frequency, and a loss of mass will cause an increase in frequency. The Sauerbrey equation (Equation (1)) is used to evaluate the proportional relationship between the values of the change in frequency $\Delta f$ to the values of the change in mass $(\Delta m)[48]$.

$$
\Delta m=-C_{f} \Delta f
$$

The mass loading of the $10 \mathrm{MHz}$ AT-cut quartz crystal microbalance sensor surfaces after protein exposure can be quantified using Equation (1), where $C_{f}$ (the mass sensitivity constant) is $-226 \mu \mathrm{g} \mathrm{Hz} \mathrm{cm}^{-2}$.

\subsection{Ellipsometry Measurements}

A Rudolph Auto EL III ellipsometer equipped with a He-Ne laser $(632.8 \mathrm{~nm})$ at an incident angle set of $70^{\circ}$ and a refractive index set to 1.45 (the commonly accepted refractive index value for thiol-based SAM films) [12,32] was used to obtain the monolayer thickness for all samples. The thickness values reported are an average of 24 measurements ( 2 measurements per slide with 4 slides for each adsorbate via 3 independent trials). The uncertainties in the thickness values correspond to the measured experimental variance in the values obtained for the indicated SAMs. After the gold substrates were immersed in ethanol solutions of the adsorbate at room temperature for $48 \mathrm{~h}$ for thin-film formation, the thickness of the SAMs was measured. After the formation of SAMs, the thin films were immersed in the protein solutions for $1 \mathrm{~h}$, separately, to allow the surface to become saturated with the protein. The films were rinsed with PBS and water and then dried under a stream of ultra-pure nitrogen gas prior to measuring the ellipsometric thickness again to determine changes in thickness due to protein exposure. The change in thickness was calculated by subtracting optical thickness of the initial SAM from the total optical thickness measurement of the SAM after exposure to the protein. The reported optical thickness measurements of the SAMs after protein exposure are an average of 6 measurements ( 2 measurements per slide with 3 individual trials per adsorbate and protein). All surfaces (evaporated gold, SPR, QCM sensors, and flat gold) were characterized for the formation of the SAMs using ellipsometry. Ellipsometric values were reported from the evaporated gold surface, but no distinguishable differences in SAM thickness or in thickness after protein exposure were observed between the evaporated gold, SPR, or QCM gold sensor surfaces.

\section{Results and Discussion}

To evaluate protein adsorption, SAMs surfaces were monitored before, during, and after protein exposure. In this study, four different proteins were selected to determine their adhesion to the SAM surfaces. The protein selections were based on criteria, including molecular weight, size, hydrophobicity, isoelectric point (pI), and applications. We chose commonly used proteins, including bovine serum albumin (BSA), a stable, moderatesize, and hydrophobic protein [49]; fibrinogen, a large, high-molecular-weight, and sticky protein with a neutral isoelectric point [50,51]; lysozyme, a small, low-molecular-weight protein with a positive charge [52]; and protamine, a low-molecular-weight protein with a pI of 12.1 [53]. Table 1 provides detailed information about the selected proteins. Since all the selected proteins are compatible with phosphate buffer solution (PBS), PBS was used as the solvent medium for the protein solution preparations. To ensure integrity of the analyses, all films were monitored for possible changes that could be associated with exposure to the buffer solution [54,55]; however, we observed no significant changes during these processes. The non-specific adsorption of the selected proteins on the SAM surfaces (including surface coverage and the amount of protein adsorbed on the surface) were measured using surface plasmon resonance spectroscopy (SPR), quartz crystal microbalance (QCM), and ellipsometry. 
Table 1. Physical properties of proteins examined in this investigation [49-53].

\begin{tabular}{ccccc}
\hline Protein & Protamine & Lysozyme & BSA & Fibrinogen \\
\hline Molecular weight & $4 \mathrm{KDa}$ & $14 \mathrm{KDa}$ & $55 \mathrm{KDa}$ & $340 \mathrm{KDa}$ \\
Size & $5 \AA \AA^{\mathrm{c}}$ & $18 \AA \AA^{\mathrm{c}}$ & $140 \times 40 \times 40 \AA$ & $450 \times 90 \AA$ \\
Shape & Spherical & Stubby prolate ellipsoid & Prolate ellipsoid $^{\mathrm{a}}$ & Cylindrical $^{\mathrm{b}}$ \\
pI & 12.1 & 11.1 & 4.8 & 5.7 \\
Application & Insulin & Cell & Blood & Muscle/Tissue \\
\hline
\end{tabular}

$\mathrm{a} a=\mathrm{b}<\mathrm{c} ;{ }^{\mathrm{b}}$ with round ends; ${ }^{\mathrm{c}}$ diameter.

\subsection{In Situ Analysis of Protein Adsorption Using SPR Spectroscopy}

Surface plasmon resonance spectroscopy provides a convenient probe to monitor in situ the interactions of proteins with surfaces $[41,56]$. This technique generates sensorgrams arising from the change of response units correlated to the amount of nonspecific proteins that adsorb on the surfaces of SAMs. The sensorgrams reporting the response changes for the interactions between each of the selected proteins and the SAM surfaces are displayed in Figure 2.
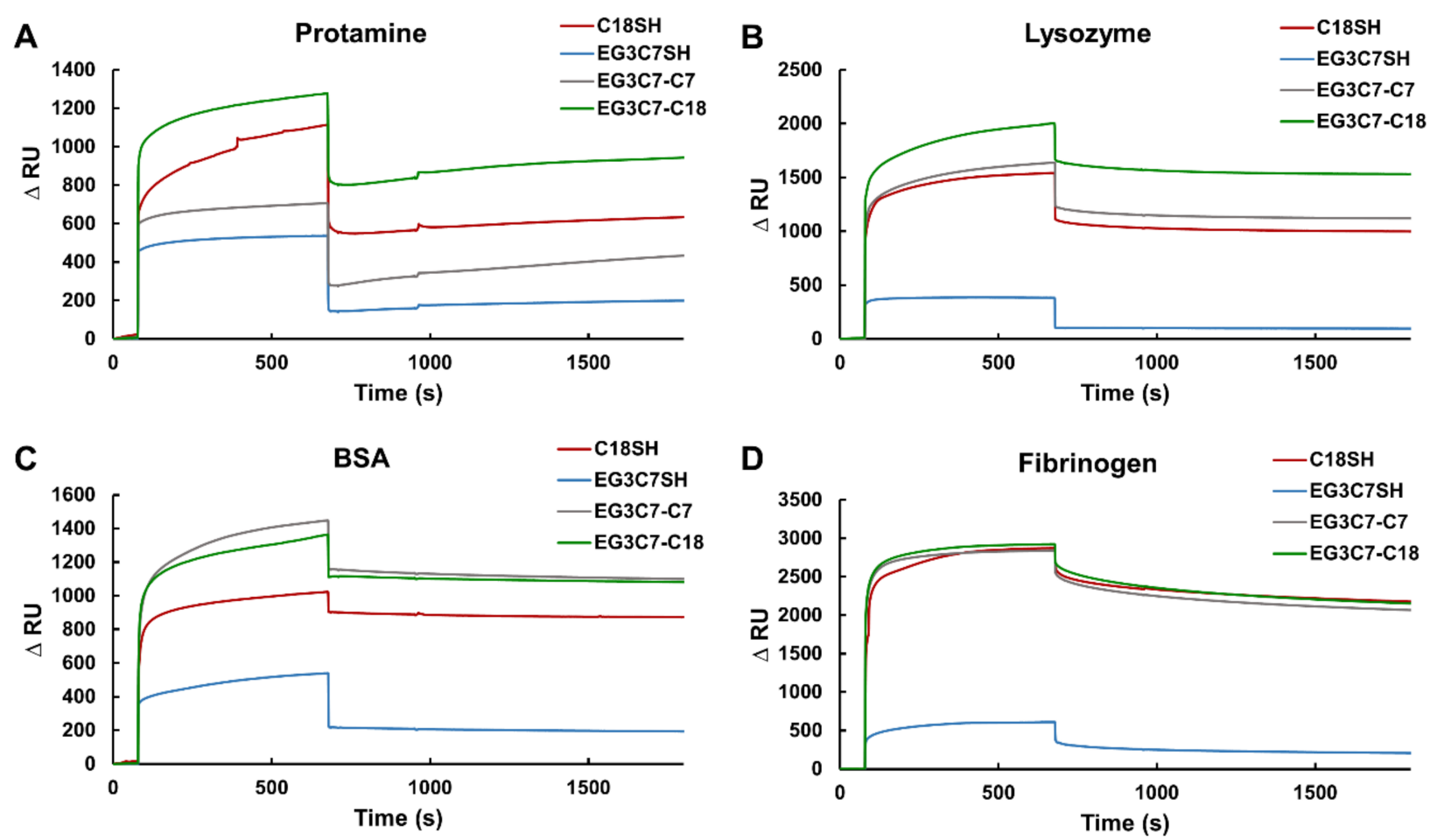

Figure 2. SPR sensorgrams of the SAMs derived from C18SH, EG3C7SH, EG3C7-C7, and EG3C7-C18 exposed to (A) protamine, (B) lysozyme, (C) BSA, and (D) fibrinogen. Protein solutions were prepared at a concentration of $1 \mathrm{mg} / \mathrm{mL}$ in PBS buffer. The measurements were performed on three independent samples of each surface, and protein with all trends consistent with those shown here.

The calculated changes in response units $(\Delta R U)$ were obtained by subtracting the final response unit values from the baseline values; these results are summarized in Table 2 and graphically presented in Figure 3. For all proteins examined, the SPR data showed that the SAMs generated from EG3C7SH were consistently more resistant to protein adsorption than the SAMs derived from C18SH, EG3C7-C7, and EG3C7-C18. For example, fibrinogen produced $\triangle R U$ values of 201, 2285, 2194, and 2295 for SAMs generated from EG3C7SH, C18SH, EG3C7-C7, and EG3C7-C18, respectively. Here, as with the other proteins, the strictly oligo(ethylene glycol)-terminated EG3C7SH SAMs exhibited the most substantial protein resistance. In contrast, due to its hydrophobic nature, C18SH SAMs adsorbed larger amounts of proteins and generated larger $\triangle R U$ values than EG3C7SH SAMs. Similarly, the 
mixed SAMs derived from EG3C7-C7 and EG3C7-C18 were markedly less protein resistant than the OEG SAMs derived from EG3C7SH.

Table 2. Values of $\triangle \mathrm{RU}$ for the SAMs after exposure to the protein solutions.

\begin{tabular}{ccccc}
\hline \multirow{2}{*}{ SAM } & \multicolumn{4}{c}{$\Delta$ RU } \\
\cline { 2 - 5 } & Protamine & Lysozyme & BSA & Fibrinogen \\
\hline C18SH & $599 \pm 3$ & $1029 \pm 42$ & $899 \pm 63$ & $2285 \pm 222$ \\
EG3C7SH & $173 \pm 11$ & $108 \pm 20$ & $195 \pm 53$ & $201 \pm 46$ \\
EG3C7-C7 & $368 \pm 87$ & $1163 \pm 77$ & $1121 \pm 145$ & $2194 \pm 122$ \\
EG3C7-C18 & $936 \pm 48$ & $1524 \pm 80$ & $1051 \pm 96$ & $2295 \pm 24$ \\
\hline
\end{tabular}

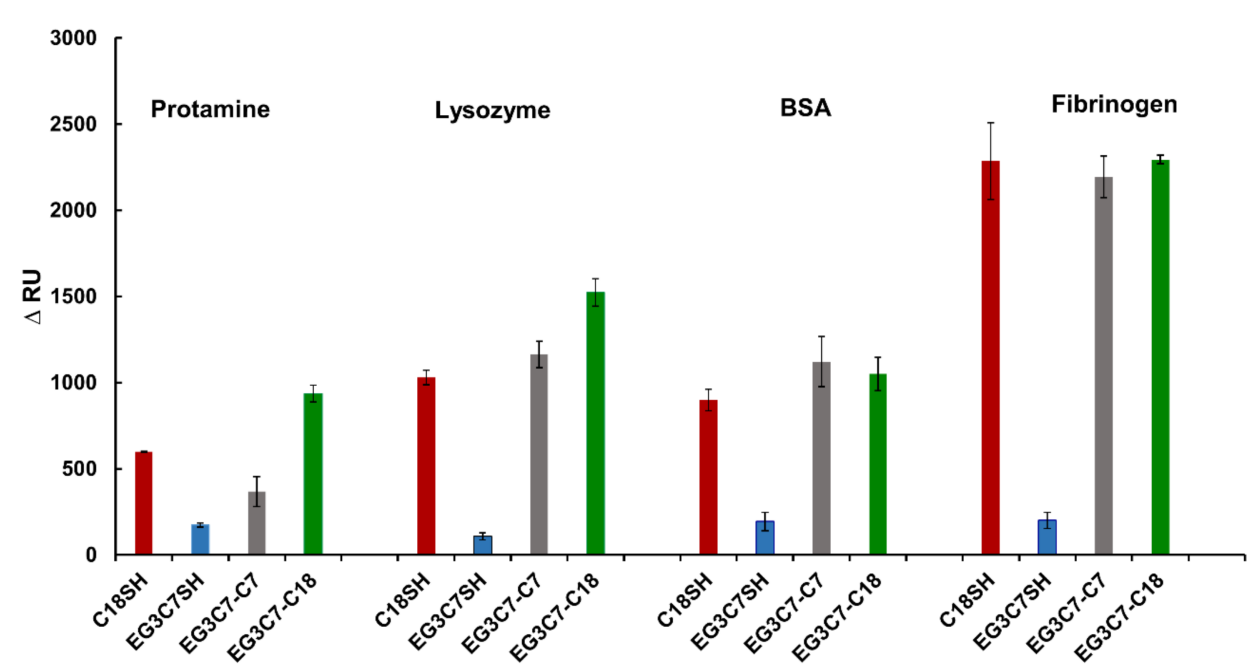

Figure 3. Graphical representation of the $\triangle R U$ values for the SAMs after exposure to the protein solutions.

\subsection{Ex Situ Analysis of Protein Adsorption Using QCM}

QCM is an analytical technique with great sensitivity for monitoring mass changes $[49,52,57]$, allowing quantification of the amount of material adsorbed on the SAM surfaces [41]. The changes in frequency $(\Delta f)$ reported as a function of time after 1 $\mathrm{h}$ exposure to $1 \mathrm{mg} / \mathrm{mL}$ of proteins in PBS are presented in Figure 4 and are averages of three independent trials for each surface. Once protein was adsorbed onto a SAM surface, a decrease in frequency compared to the SAM-coated QCM gold sensor was observed. Since QCM is an ex situ technique, it generates signals in the absence of a hydration layer. These signals are known as the dry mass loading of proteins, which should be smaller than the values obtained from the in situ measurements by SPR that include hydration layers $[58,59]$. Notably, the same trends were observed in both the in situ and the ex situ studies. The mass loadings for each of the selected proteins on the SAM surfaces were calculated using Equation (1) and are presented in Table 3 numerically and Figure 5 graphically. After exposing the SAMs to fibrinogen solutions, for example, mass increases of 119 $\mathrm{ng} / \mathrm{cm}^{2}, 854 \mathrm{ng} / \mathrm{cm}^{2}, 471 \mathrm{ng} / \mathrm{cm}^{2}$, and $943 \mathrm{ng} / \mathrm{cm}^{2}$ were recorded for SAMs generated from EG3C7SH, C18SH, EG3C7-C7, and EG3C7-C18, respectively. Notably, the EG3C7SH SAMs showed lower mass loadings than the hydrophobic C18SH SAMs as well as the mixed bidentate EG3C7-C7 and EG3C7-C18 SAMs. Similar trends were observed for BSA and lysozyme. In addition, while the mass loadings for protamine were not inconsistent with the general trend, the relatively large experimental error in the values preclude us from making any strong claims. These findings are thus largely consistent with the SPR data reported above and the ellipsometry data presented below (vide infra). 

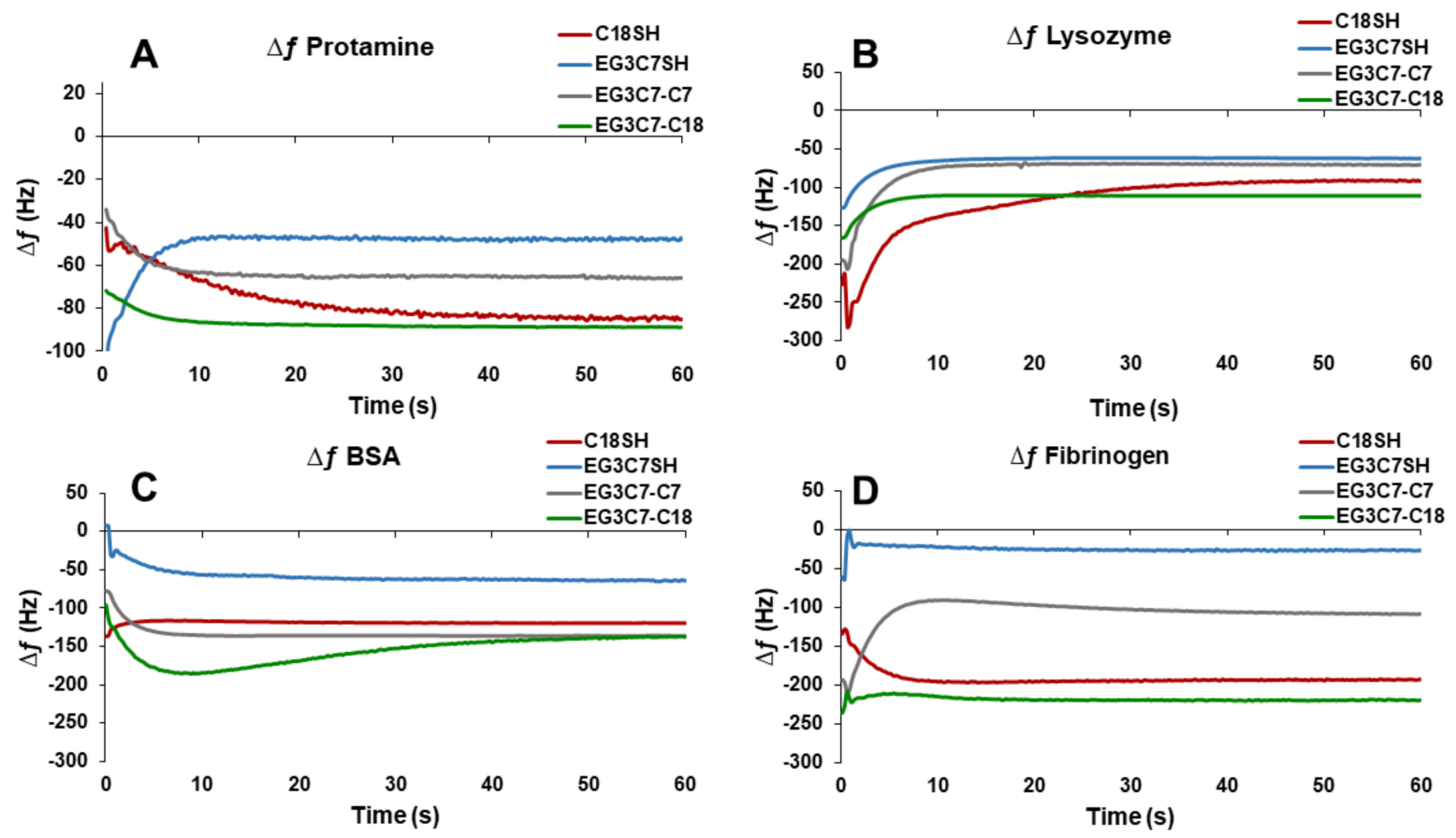

Figure 4. Change in frequency vs. time for SAMs derived from C18SH, EG3C7SH, and EG3C7-C7, and EG3C7-C18 after $1 \mathrm{~h}$ exposure to $1 \mathrm{mg} / \mathrm{mL}$ of protein in PBS solution: (A) protamine, (B) lysosome, (C) BSA, and (D) fibrinogen.

Table 3. Calculated values for protein mass loading on the SAMs derived from C18SH, EG3C7SH, EG3C7-C7, and EG3C7-C18 after $1 \mathrm{~h}$ exposure to $1 \mathrm{mg} / \mathrm{mL}$ of protein in PBS.

\begin{tabular}{ccccc}
\hline \multirow{2}{*}{ SAM } & \multicolumn{4}{c}{ Protein Loading $\mathbf{( n g / \mathbf { c m } ^ { \mathbf { 2 } } )}$} \\
\cline { 2 - 5 } & Protamine & Lysozyme & BSA & Fibrinogen \\
\hline C18SH & $329 \pm 34$ & $409 \pm 67$ & $493 \pm 76$ & $854 \pm 80$ \\
EG3C7SH & $218 \pm 94$ & $264 \pm 12$ & $223 \pm 75$ & $119 \pm 30$ \\
EG3C7-C7 & $308 \pm 40$ & $314 \pm 62$ & $621 \pm 72$ & $471 \pm 52$ \\
EG3C7-C18 & $398 \pm 45$ & $442 \pm 76$ & $644 \pm 99$ & $943 \pm 83$ \\
\hline
\end{tabular}

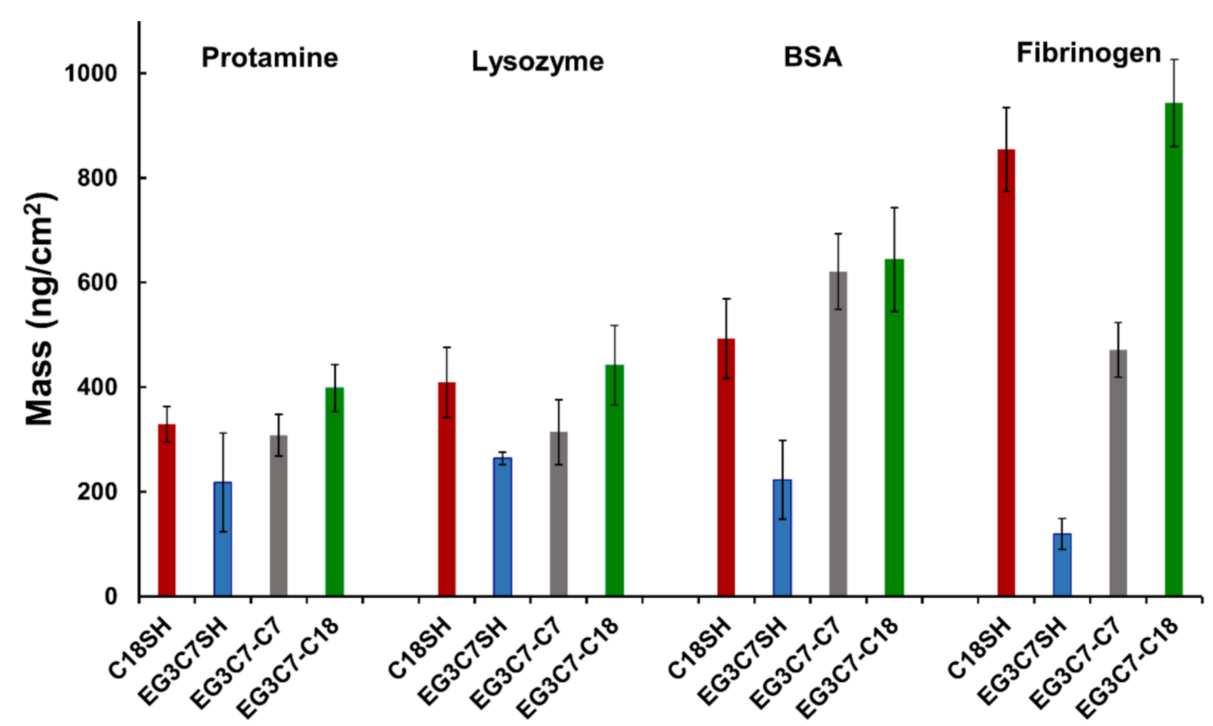

Figure 5. Graphical presentation of the calculated values for the mass loading of proteins on the SAMs derived from C18SH, EG3C7SH, EG3C7-C7, and EG3C7-C18 after exposure to $1 \mathrm{mg} / \mathrm{mL}$ protein solutions in PBS for $1 \mathrm{~h}$. 


\subsection{Ellipsometric Thickness Measurements}

To confirm the formation of monolayers from the various adsorbates, we collected ellipsometric thickness data for all SAMs. The thickness measurements obtained were consistent with previously reported values [39]: $23 \pm 1 \AA$ (C18SH), $17 \pm 1 \AA$ (EG3C7SH), $10 \pm 1 \AA$ (EG3C7-C7), and $12 \pm 1 \AA$ (EG3C7-C18). We then subjected each of the SAMs to the four selected protein solutions and measured the corresponding ellipsometric thicknesses. Table 4 lists the numerical values for the changes in thickness after protein exposure, while Figure 6 graphically presents the values. The changes in ellipsometric thickness further support the SPR and particularly the QCM results, confirming that the presence of hydrocarbon chains in the SAMs derived from the bidentate adsorbate molecules EG3C7C7 and EG3C7-C18 gives rise to SAM coatings with diminished antifouling performance when compared to EG3C7SH SAMs.

Table 4. Changes in ellipsometric thickness of the SAMs generated from C18SH, EG3C7SH, EG3C7C7, and EG3C7-C18 after exposure to $1 \mathrm{mg} / \mathrm{mL}$ of protein solutions.

\begin{tabular}{ccccc}
\hline \multirow{2}{*}{ SAM } & \multicolumn{4}{c}{$\Delta$ Thickness (̊̊) } \\
\cline { 2 - 5 } & Protamine & Lysozyme & BSA & Fibrinogen \\
\hline C18SH & $11 \pm 5$ & $20 \pm 2$ & $13 \pm 8$ & $43 \pm 2$ \\
EG3C7SH & $2 \pm 2$ & $2 \pm 1$ & $2 \pm 3$ & $3 \pm 1$ \\
EG3C7-C7 & $3 \pm 3$ & $19 \pm 2$ & $8 \pm 2$ & $27 \pm 1$ \\
EG3C7-C18 & $9 \pm 4$ & $20 \pm 7$ & $16 \pm 4$ & $39 \pm 2$ \\
\hline
\end{tabular}

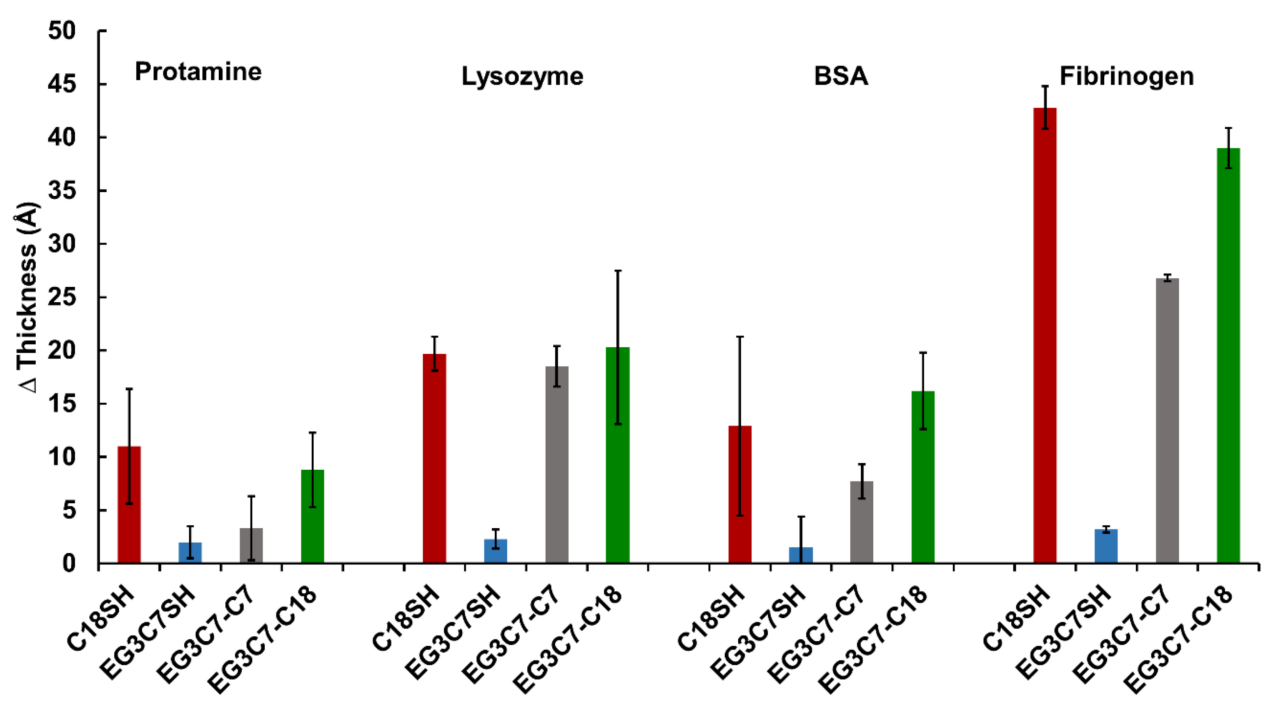

Figure 6. Changes in the thickness of the SAMs generated from C18SH, EG3C7SH, EG3C7-C7, and EG3C7-C18 after exposure to PBS solutions of protamine, lysozyme, BSA, and fibrinogen.

\subsection{Wettability of the SAMs}

To evaluate the hydrophobic and hydrophilic properties of the SAMs, we measured the advancing contact angles $\left(\theta a,{ }^{\circ}\right)$ of water on the surfaces of the SAMs derived from each adsorbate. The average advancing contact angle of water on the hydrophobic C18SH SAMs was consistent with previously reported values $\left(\theta_{a}=115^{\circ}\right)$ [39]. Interestingly, while the average advancing contact angle of water on the SAMs derived from EG3C7-C7 was similar to that for the SAMs derived from EG3C7SH $\left(\theta_{\mathrm{a}} \sim 63^{\circ}\right.$ for both), the SAMs derived from EG3C7-C18 were substantially less wettable $\left(\theta_{\mathrm{a}}=83^{\circ}\right)$ than the EG3C7-C7 and EG3C7SH SAMs [39]. These results demonstrate that the presence of long hydrophobic alkyl chains leads to a reduction in the attractive interactions between water and the EG3C7-C18 SAMs compared to the EG3C7SH SAMs, but the presence of shorter alkyl chains in the EG3C7-C7 SAMs has little or no effect when compared to the EG3C7SH SAMs. While these results 
suggest that the antifouling properties of OEG SAMs cannot be attributed to water on the surfaces of the OEG SAMs, the results do not exclude the hypothesis proposed by Whitesides [14], Grunze [14,26], and Hayashi $[27,28]$ that water within the OEG matrixes of these SAMs is responsible.

When taken as whole, the protein adsorption studies paint a consistent picture: the single-component OEG SAMs derived from EG3C7SH are more protein resistant than the single-component SAMs derived from $\mathrm{C} 18 \mathrm{SH}$ and the mixed SAMs derived from EG3C7-C7 and EG3C7-C18. In addition, while our results shed no light on the degree of hydration of the OEG moieties in these SAMs, we find it plausible that that the presence of the hydrophobic alkyl chains in the EG3C7-C7 and EG3C7-C18 SAMs is responsible for the observed reduction in protein resistance for these SAMs. As noted in our previous study [39], the reduction in protein resistance can be attributed to (1) diminished binding of interfacial water within the SAMs leading to stronger interactions between the proteins and the surfaces and/or (2) attractive hydrophobic interactions between the alkyl chains directly contacting the protein molecules.

\section{Conclusions}

SAMs derived from the monodentate hydrocarbon thiol $\mathrm{C} 18 \mathrm{SH}$, the monodentate tri(ethylene glycol)-terminated thiol EG3C7SH, and the bidentate unsymmetrical spiroalkanedithiols containing both oligo(ethylene glycol) and hydrocarbon tailgroups EG3C7-C7 and EG3C7-C18 were exposed to a diverse range of proteins (protamine, lysozyme, bovine serum albumin (BSA), and fibrinogen) to evaluate their antifouling performance. The protein adsorptions were monitored by SPR, QCM, and ellipsometry as complementary techniques to obtain a deeper understanding of the protein resistance of OEG-based SAMs. The hydrophobic C18SH SAMs were markedly less protein resistant than the EG3C7SH SAMs, which are known for their protein-resistant properties. Similarly, the unsymmetrical spiroalkanedithiol-based SAMs derived from EG3C7-C18 and EG3C7-C7, which contain both oligo(ethylene glycol) and hydrocarbon tailgroups, showed diminished antifouling performance compared to the EG3C7SH SAMs. Our studies are therefore consistent with a model in which the introduction of hydrophobic hydrocarbon chains into the hydrophilic OEG matrix limits the penetration of water molecules into the interior of the SAMs, thereby diminishing the steric repulsion of the OEG chains and leading to enhanced interactions between the SAMs and the proteins (i.e., enhanced protein adsorption).

Author Contributions: Conceptualization, T.R.L.; investigation, L.R.S.H. and J.W.C.J.; methodology, P.C. and H.J.L.; data curation, L.R.S.H., H.-V.T. and M.D.M.; writing-original draft, L.R.S.H.; writing-review and editing, H.-V.T., M.D.M. and T.R.L.; supervision, T.R.L. All authors have read and agreed to the published version of the manuscript.

Funding: The authors are grateful for financial support from the National Science Foundation (CHE-1710561), the Robert A. Welch Foundation (grant no. E-1320), and the Texas Center for Superconductivity at the University of Houston.

Data Availability Statement: The data presented in this study are available on request from the corresponding author.

Conflicts of Interest: The authors declare no conflict of interest.

\section{References}

1. Banerjee, I.; Pangule, R.C.; Kane, R.S. Antifouling Coatings: Recent Developments in the Design of Surfaces That Prevent Fouling by Proteins, Bacteria, and Marine Organisms. Adv. Mater. 2011, 23, 690-718. [CrossRef]

2. Blaszykowski, C.; Sheikh, S.; Thompson, M. A Survey of State-of-the-Art Surface Chemistries to Minimize Fouling from Human and Animal Biofluids. Biomater. Sci. 2015, 3, 1335-1370. [CrossRef]

3. Jiang, C.; Wang, G.; Hein, R.; Liu, N.; Luo, X.; Davis, J.J. Antifouling Strategies for Selective In Vitro and In Vivo Sensing. Chem. Rev. 2020, 120, 3852-3889. [CrossRef] [PubMed]

4. Lahiri, J.; Kalal, P.; Frutos, A.G.; Jonas, S.J.; Schaeffler, R. Method for Fabricating Supported Bilayer Lipid Membranes on Gold. Langmuir 2000, 16, 7805-7810. [CrossRef] 
5. Lee, H.-H.; Gavutis, M.; Ruželè, Ž.; Valiokas, R.; Liedberg, B. Mixed Self-Assembled Monolayers with Terminal Deuterated Anchors: Characterization and Probing of Model Lipid Membrane Formation. J. Phys. Chem. B 2018, 122, 8201-8210. [CrossRef]

6. Herrwerth, S.; Rosendahl, T.; Feng, C.; Fick, J.; Eck, W.; Himmelhaus, M.; Dahint, R.; Grunze, M. Covalent Coupling of Antibodies to Self-Assembled Monolayers of Carboxy-Functionalized Poly(ethylene glycol): Protein Resistance and Specific Binding of Biomolecules. Langmuir 2003, 19, 1880-1887. [CrossRef]

7. Castner, D.G.; Ratner, B.D. Biomedical Surface Science: Foundations to Frontiers. Surf. Sci. 2002, 500, 28-60. [CrossRef]

8. Ko, B.S.; Babcock, B.; Jennings, G.K.; Tilden, S.G.; Peterson, R.R.; Cliffel, D.; Greenbaum, E. Effect of Surface Composition on the Adsorption of Photosystem I onto Alkanethiolate Self-Assembled Monolayers on Gold. Langmuir 2004, 20, 4033-4038. [CrossRef]

9. Sofia, S.J.; Premnath, V.; Merrill, E.W. Poly(ethylene oxide) Grafted to Silicon Surfaces: Grafting Density and Protein Adsorption. Macromolecules 1998, 31, 5059-5070. [CrossRef]

10. Clare, T.L.; Clare, B.H.; Nichols, B.M.; Abbott, N.L.; Hamers, R.J. Functional Monolayers for Improved Resistance to Protein Adsorption: Oligo(ethylene glycol)-Modified Silicon and Diamond Surfaces. Langmuir 2005, 21, 6344-6355. [CrossRef]

11. Prime, K.L.; Whitesides, G.M. Self-Assembled Organic Monolayers: Model Systems for Studying Adsorption of Proteins at Surfaces. Science 1991, 252, 1164-1167. [CrossRef] [PubMed]

12. Prime, K.L.; Whitesides, G.M. Adsorption of Proteins onto Surfaces Containing End-Attached Oligo(ethylene oxide): A Model System Using Self-Assembled Monolayers. J. Am. Chem. Soc. 1993, 115, 10714-10721. [CrossRef]

13. Luk, Y.-Y.; Tingey, M.L.; Hall, D.J.; Israel, B.A.; Murphy, C.J.; Bertics, P.J.; Abbott, N.L. Using Liquid Crystals to Amplify Protein-Receptor Interactions: Design of Surfaces with Nanometer-Scale Topography That Present Histidine-Tagged Protein Receptors. Langmuir 2003, 19, 1671-1680. [CrossRef]

14. Harder, P.; Grunze, M.; Dahint, R.; Whitesides, G.M.; Laibinis, P.E. Molecular Conformation in Oligo(ethylene glycol)-Terminated Self-Assembled Monolayers on Gold and Silver Surfaces Determines Their Ability to Resist Protein Adsorption. J. Phys. Chem. B 1998, 102, 426-436. [CrossRef]

15. Feldman, K.; Hähner, G.; Spencer, N.D.; Harder, P.; Grunze, M. Probing Resistance to Protein Adsorption of Oligo(ethylene glycol)-Terminated Self-Assembled Monolayers by Scanning Force Microscopy. J. Am. Chem. Soc. 1999, 121, 10134-10141. [CrossRef]

16. Li, L.; Chen, S.; Zheng, J.; Ratner, B.D.; Jiang, S. Protein Adsorption on Oligo(ethylene glycol)-Terminated Alkanethiolate Self-Assembled Monolayers: The Molecular Basis for Nonfouling Behavior. J. Phys. Chem. B 2005, 109, 2934-2941. [CrossRef]

17. Sun, K.; Song, L.; Xie, Y.; Liu, D.; Wang, D.; Wang, Z.; Ma, W.; Zhu, J.; Jiang, X. Using Self-Polymerized Dopamine to Modify the Antifouling Property of Oligo(ethylene glycol) Self-Assembled Monolayers and Its Application in Cell Patterning. Langmuir 2011, 27, 5709-5712. [CrossRef] [PubMed]

18. Krakert, S.; Ballav, N.; Zharnikov, M.; Terfort, A. Adjustment of the Bioresistivity by Electron Irradiation: Self-Assembled Monolayers of Oligo(ethyleneglycol)-Terminated Alkanethiols with Embedded Cleavable Group. Phys. Chem. Chem. Phys. 2010, 12, 507-515. [CrossRef]

19. Zorn, S.; Skoda, M.W.A.; Gerlach, A.; Jacobs, R.M.J.; Schreiber, F. On the Stability of Oligo(ethylene glycol) (C11EG6OMe) SAMs on Gold: Behavior at Elevated Temperature in Contact with Water. Langmuir 2011, 27, 2237-2243. [CrossRef]

20. Ostuni, E.; Chapman, R.G.; Holmlin, R.E.; Takayama, S.; Whitesides, G.M. A Survey of Structure-Property Relationships of Surfaces that Resist the Adsorption of Protein. Langmuir 2001, 17, 5605-5620. [CrossRef]

21. Zheng, J.; Li, L.; Chen, S.; Jiang, S. Molecular Simulation Study of Water Interactions with Oligo (ethylene glycol)-Terminated Alkanethiol Self-Assembled Monolayers. Langmuir 2004, 20, 8931-8938. [CrossRef] [PubMed]

22. Jeon, S.I.; Lee, J.H.; Andrade, J.D.; De Gennes, P.G. Protein-Surface Interactions in the Presence of Polyethylene Oxide: I. Simplified Theory. J. Colloid Interface Sci. 1991, 142, 149-158. [CrossRef]

23. Jeon, S.I.; Andrade, J.D. Protein-Surface Interactions in the Presence of Polyethylene Oxide: II. Effect of Protein Size. J. Colloid Interface Sci. 1991, 142, 159-166. [CrossRef]

24. McPherson, T.; Kidane, A.; Szleifer, I.; Park, K. Prevention of Protein Adsorption by Tethered Poly(ethylene oxide) Layers: Experiments and Single-Chain Mean-Field Analysis. Langmuir 1998, 14, 176-186. [CrossRef]

25. Pertsin, A.J.; Grunze, M. Computer Simulation of Water near the Surface of Oligo(ethylene glycol)-Terminated Alkanethiol Self-Assembled Monolayers. Langmuir 2000, 16, 8829-8841. [CrossRef]

26. Herrwerth, S.; Eck, W.; Reinhardt, S.; Grunze, M. Factors That Determine the Protein Resistance of Oligoether Self-Assembled Monolayers-Internal Hydrophilicity, Terminal Hydrophilicity, and Lateral Packing Density. J. Am. Chem. Soc. 2003, 125, 9359-9366. [CrossRef]

27. Hayashi, T.; Tanaka, Y.; Koide, Y.; Tanaka, M.; Hara, M. Mechanism Underlying Bioinertness of Self-Assembled Monolayers of Oligo(ethyleneglycol)-Terminated Alkanethiols on Gold: Protein Adsorption, Platelet Adhesion, and Surface Forces. Phys. Chem. Chem. Phys. 2012, 14, 10196-10206. [CrossRef]

28. Sekine, T.; Tanaka, Y.; Sato, C.; Tanaka, M.; Hayashi, T. Evaluation of Factors to Determine Platelet Compatibility by Using Self-Assembled Monolayers with a Chemical Gradient. Langmuir 2015, 31, 7100-7105. [CrossRef]

29. Sayin, M.; Nefedov, A.; Zharnikov, M. Interaction of Water with Oligo(ethylene glycol) Terminated Monolayers: Wetting versus Hydration. Phys. Chem. Chem. Phys. 2020, 22, 8088-8095. [CrossRef]

30. Bain, C.D.; Troughton, E.B.; Tao, Y.T.; Evall, J.; Whitesides, G.M.; Nuzzo, R.G. Formation of Monolayer Films by the Spontaneous Assembly of Organic Thiols from Solution onto Gold. J. Am. Chem. Soc. 1989, 111, 321-335. [CrossRef] 
31. Chinwangso, P.; Jamison, A.C.; Lee, T.R. Multidentate Adsorbates for Self-Assembled Monolayer Films. Acc. Chem. Res. 2011, 44, 511-519. [CrossRef] [PubMed]

32. Shon, Y.-S.; Lee, T.R. Chelating Self-Assembled Monolayers on Gold Generated from Spiroalkanedithiols. Langmuir 1999, 15, 1136-1140. [CrossRef]

33. Shon, Y.-S.; Lee, T.R. Desorption and Exchange of Self-Assembled Monolayers (SAMs) on Gold Generated from Chelating Alkanedithiols. J. Phys. Chem. B 2000, 104, 8192-8200. [CrossRef]

34. Shon, Y.-S.; Lee, S.; Perry, S.S.; Lee, T.R. The Adsorption of Unsymmetrical Spiroalkanedithiols onto Gold Affords MultiComponent Interfaces That Are Homogeneously Mixed at the Molecular Level. J. Am. Chem. Soc. 2000, 122, $1278-1281$. [CrossRef]

35. Shon, Y.-S.; Lee, S.; Colorado, R.; Perry, S.S.; Lee, T.R. Spiroalkanedithiol-Based SAMs Reveal Unique Insight into the Wettabilities and Frictional Properties of Organic Thin Films. J. Am. Chem. Soc. 2000, 122, 7556-7563. [CrossRef]

36. Hoang, J.; Park, C.S.; Marquez, M.D.; Gunaratne, P.H.; Lee, T.R. DNA Binding on Self-Assembled Monolayers Terminated with Mixtures of Ammonium and Trimethylammonium Groups: Toward a Gene-Delivery Platform. ACS Appl. Nano Mater. 2020, 3 , 6621-6628. [CrossRef]

37. Sakunkaewkasem, S.; Gonzalez, M.A.; Marquez, M.D.; Lee, T.R. Olefin-Bridged Bidentate Adsorbates for Generating SelfAssembled Monolayers on Gold. Langmuir 2020, 36, 10699-10707. [CrossRef]

38. Chinwangso, P.; Lee, H.J.; Lee, T.R. Self-Assembled Monolayers Generated from Unsymmetrical Partially Fluorinated Spiroalkanedithiols. Langmuir 2015, 31, 13341-13349. [CrossRef]

39. Chinwangso, P.; Lee, H.J.; Jamison, A.C.; Marquez, M.D.; Park, C.S.; Lee, T.R. Structure, Wettability, and Thermal Stability of Organic Thin-Films on Gold Generated from the Molecular Self-Assembly of Unsymmetrical Oligo(ethylene glycol) Spiroalkanedithiols. Langmuir 2017, 33, 1751-1762. [CrossRef]

40. Chinwangso, P.; St. Hill, L.R.; Marquez, M.D.; Lee, T.R. Unsymmetrical Spiroalkanedithiols Having Mixed Fluorinated and Alkyl Tailgroups of Varying Length: Film Structure and Interfacial Properties. Molecules 2018, 23, 2632. [CrossRef] [PubMed]

41. St. Hill, L.R.; Craft, J.W.; Chinwangso, P.; Tran, H.-V.; Marquez, M.D.; Lee, T.R. Antifouling Coatings Generated from Unsymmetrical Partially Fluorinated Spiroalkanedithiols. ACS Appl. Bio Mater. 2021, 4, 1563-1572. [CrossRef]

42. Smith, R.K.; Reed, S.M.; Lewis, P.A.; Monnell, J.D.; Clegg, R.S.; Kelly, K.F.; Bumm, L.A.; Hutchison, J.E.; Weiss, P.S. Phase Separation within a Binary Self-Assembled Monolayer on Au\{111\} Driven by an Amide-Containing Alkanethiol. J. Phys. Chem. B 2001, 105, 1119-1122. [CrossRef]

43. Jackson, A.M.; Myerson, J.W.; Stellacci, F. Spontaneous Assembly of Subnanometre-Ordered Domains in the Ligand Shell of Monolayer-Protected Nanoparticles. Nat. Mater. 2004, 3, 330-336. [CrossRef] [PubMed]

44. Yaliraki, S.N.; Longo, G.; Gale, E.; Szleifer, I.; Ratner, M.A. Stability and Phase Separation in Mixed Self-Assembled Monolayers. J. Chem. Phys. 2006, 125, 074708. [CrossRef] [PubMed]

45. Fetisov, E.O.; Siepmann, J.I. Structure and Phase Behavior of Mixed Self-Assembled Alkanethiolate Monolayers on Gold Nanoparticles: A Monte Carlo Study. J. Phys. Chem. B 2016, 120, 1972-1978. [CrossRef]

46. Gao, J.; Lin, H.; Qin, X.; Zhang, X.; Ding, H.; Wang, Y.; Rokni Fard, M.; Kaya, D.; Zhu, G.; Li, Q.; et al. Probing Phase Evolutions of Au-Methyl-Propyl-Thiolate Self-Assembled Monolayers on Au(111) at the Molecular Level. J. Phys. Chem. B 2018, 122, 6666-6672. [CrossRef]

47. Akimov, Y.; Pam, M.E.; Sun, S. Kretschmann-Raether Configuration: Revision of the Theory of Resonant Interaction. Phys. Rev. B 2017, 96, 155433. [CrossRef]

48. Buttry, D.A.; Ward, M.D. Measurement of Interfacial Processes at Electrode Surfaces with the Electrochemical Quartz Crystal Microbalance. Chem. Rev. 1992, 92, 1355-1379. [CrossRef]

49. Tsai, D.-H.; DelRio, F.W.; Keene, A.M.; Tyner, K.M.; MacCuspie, R.I.; Cho, T.J.; Zachariah, M.R.; Hackley, V.A. Adsorption and Conformation of Serum Albumin Protein on Gold Nanoparticles Investigated Using Dimensional Measurements and in Situ Spectroscopic Methods. Langmuir 2011, 27, 2464-2477. [CrossRef]

50. Pietrocola, G.; Visai, L.; Valtulina, V.; Vignati, E.; Rindi, S.; Arciola, C.R.; Piazza, R.; Speziale, P. Multiple Interactions of FbsA, a Surface Protein from Streptococcus Agalactiae, with Fibrinogen: Affinity, Stoichiometry, and Structural Characterization. Biochemistry 2006, 45, 12840-12852. [CrossRef]

51. Furlan, M. Sticky and Promiscuous Plasma Proteins Maintain the Equilibrium between Bleeding and Thrombosis. Swiss Med. Wkly. 2002, 132, 181-189.

52. Colvin, J.R. The Size and Shape of Lysozyme. Can. J. Chem. 1952, 30, 831-834. [CrossRef]

53. He, H.; Ye, J.; Liu, E.; Liang, Q.; Liu, Q.; Yang, V.C. Low Molecular Weight Protamine (LMWP): A Nontoxic Protamine Substitute and an Effective Cell-Penetrating Peptide. J. Control. Release 2014, 193, 63-73. [CrossRef]

54. Marucco, A.; Catalano, F.; Fenoglio, I.; Turci, F.; Martra, G.; Fubini, B. Possible Chemical Source of Discrepancy between in Vitro and in Vivo Tests in Nanotoxicology Caused by Strong Adsorption of Buffer Components. Chem. Res. Toxicol. 2015, $28,87-91$. [CrossRef]

55. Parkes, M.; Myant, C.; Cann, P.M.; Wong, J.S.S. The Effect of Buffer Solution Choice on Protein Adsorption and Lubrication. Tribol. Int. 2014, 72, 108-117. [CrossRef]

56. Bakhtiar, R. Surface Plasmon Resonance Spectroscopy: A Versatile Technique in a Biochemist's Toolbox. J. Chem. Educ. 2013, 90, 203-209. [CrossRef] 
57. Höök, F.; Rodahl, M.; Kasemo, B.; Brzezinski, P. Structural Changes in Hemoglobin during Adsorption to Solid Surfaces: Effects of PH, Ionic Strength, and Ligand Binding. Proc. Natl. Acad. Sci. USA 1998, 95, 12271-12276. [CrossRef]

58. Rickert, J.; Brecht, A.; Göpel, W. Quartz Crystal Microbalances for Quantitative Biosensing and Characterizing Protein Multilayers. Biosens. Bioelectron. 1997, 12, 567-575. [CrossRef]

59. Levi, M.D.; Daikhin, L.; Aurbach, D.; Presser, V. Quartz Crystal Microbalance with Dissipation Monitoring (EQCM-D) for in-Situ Studies of Electrodes for Supercapacitors and Batteries: A Mini-Review. Electrochem. Commun. 2016, 67, 16-21. [CrossRef] 